\title{
THE EFFECTS OF SEX STEROID HORMONES UPON LONGEVITY IN RATS
}

\author{
S. A. ASDELL, H. DOORNENBAL, * S. R. JOSHI $\dagger$ AND \\ G. A. SPERLING \\ Animal Science Department, Cornell University, Ithaca, New York
}

(Received 27th May 1966)

\begin{abstract}
Summary. Eleven groups of fifty rats each were kept under uniform conditions of management and their life-spans under different treatments were compared. Females lived longer than males, while ovariectomy tended to shorten the life-span of females and castration to lengthen that of males. Implantation of gonadectomized rats with oestradiol benzoate did not prolong the life-span of the females but it did tend to prolong that of males. Implantation of gonadectomized rats with testosterone propionate tended to shorten the average life-span of both sexes. Unbred females outlived bred ones, on the average, but the difference was not significant at the $5 \%$ level. Late initial breeding appeared to be more harmful than breeding for the first time at the usual age for laboratory rats. Light breeding had little or no effect upon the average longevity of males. These conclusions are tentative. The results are consistent but they mostly lack acceptable statistical significance. The most significant result statistically was that rats exposed to their own or implanted oestrogens had a longer average life-span than did those exposed to their own or to implanted testosterone.
\end{abstract}

\section{INTRODUCTION}

It is well known that in man the average life-span of the female is longer than that of the male. For white natives of the United States the average life expectation at birth in the years 1939 to 1941 was 67.3 years for women and 62.8 years for men (Dublin, Lotka \& Spiegelman, 1949). Hamilton (1948) has assembled data that show that, with few exceptions, the female, vertebrate or invertebrate, has a longer average life-span than does the male. This rules out speculation that in man the difference is due to greater hazards or wear and tear of employment which might shorten his life. Hamilton also analysed human mortality statistics for a variety of diseases and showed that very many of them took a greater toll of males than of females at most ages. He concluded on general grounds that testosterone causes the shorter life expectancy of the male. This is a hypothesis that is easily tested by experiments with a laboratory species.

* Present address: Dominion Experimental Farm, Lacombe, Alberta, Canada.

† Present address: Children's Cancer Research Foundation, Boston, Massachusetts. 
The rat is no exception to the rule of a differential life-span. In eight strains tested by Curtis, Dunning \& Bullock (1933), the male life-span was the shorter by 0.1 to 2.4 months in average spans of from 11.1 to 21.7 months. Robertson, Marston \& Walters (1934) reported an average life-span for female rats of 773 days and for males of 712 days, while for the Cornell Nutrition colony McCay, Sperling \& Barnes (1943) found that the average life of the females was 687 days and of the males, 622 days. The difference, about $10 \%$, is of the same degree as that for man.

Slonaker (1930) has reported the average life-span of ten normal male rats in his colony as $788 \pm 22$ (P.E.) days, and of eight castrates as $770 \pm 28$ days, while seventeen normal unbred females lived for $863 \pm 28$ days and thirtyseven ovariectomized ones lived for $755 \pm 22$ days. These results indicate that castration does not prolong life as it should on Hamilton's hypothesis. On the other hand, ovariectomy shortened the life-span of these rats by a wide margin, bringing it down to the level of the males. These results indicate that the presence of ovaries is conducive to a longer life-span. But the small and variable number of rats in Slonaker's groups make these conclusions subject to doubt because direct comparison is difficult.

In mice, Mühlbock (1959 a, b) found that castrated males outlived normal ones by a very slight margin, while ovariectomized females had slightly shorter lives than had virgin females. These conclusions may be drawn from the curves given in the paper. Unfortunately, no statistical analysis nor averages are given. Mice show strain differences in relative longevity of the sexes; in some, males and females live for approximately equal periods, in others, and Mühlbock's mice fall into this category, the usual greater female life-span has been found. However, these results tend to support Slonaker's (1930) findings.

Hamilton (1965) has compared the average life-span of cats brought to two hospitals. In one series, castrate males had a mean life-span of 8.2 years while normal males averaged 3.8 years. In his second series the castrate averaged 8.8 years and the normals 7.7 years. Both series gave an advantage to the castrates. Spayed females had a slight, but insignificantly longer span than did intact females.

We have attempted to determine the nature and extent of gonadal influence upon longevity in rats by the obvious method of comparing the life-spans of normal and gonadectomized animals. Furthermore, we have attempted to compare rats with hormonic 'reversals' by periodic implants of oestrogens or androgens into gonadectomized rats of both sexes. At the same time we have included groups of bred males and females to compare the effects of breeding with its absence. Most previous comparisons have been made in unbred animals.

\section{MATERIAL AND METHODS}

The rats used in this study were from the Cornell Nutrition colony. This strain was derived about 30 years previously from the Osborne-Mendel Yale strain. The colony has been a closed one from its beginning but no attempt has been made to inbreed. Compared with Wistar rats and their derivative strains these rats are small, slow-growing and produce relatively small litters. They seem to 
be more susceptible in early life to bronchial disorders than are the Wistar strains. As litters were weaned at 3 weeks old eleven groups were set up in such a way that more than one rat from a litter was rarely assigned to the same group. Assignment to individual groups was made on a random basis until fifty rats were in each group. Five rats were assigned to a cage and the arrangement of these cages in the racks was such that no group had an advantage of position. Where the females were to be bred a male from the breeding group was placed in a cage. The females were palpated daily and when one was found to be pregnant she was removed to a separate cage and kept in it until her litter was weaned at 3 weeks when she was returned to her breeding cage. Males were rotated from cage to cage at weekly intervals and when the males of the breeding group became obviously unfit for further breeding young males were introduced to improve the probability that the females would be bred.

The pellets that were used in making subcutaneous implants were kindly made for us by Dr Robert H. Silber, Merck Institute of Therapeutic Research. Their composition was as follows:

$\begin{array}{lcc} & \begin{array}{c}\text { Testosterone } \\ \text { pellets }(\mathrm{mg})\end{array} & \begin{array}{c}\text { Oestrogen } \\ \text { pellets }(\mathrm{mg})\end{array} \\ \text { Cholesterol } & 19.45 & 19 \cdot 45 \\ \text { Dibasic calcium phosphate } & 30 & 30 \\ \text { Corn starch } & 2 \cdot 63 & 3.05 \\ \text { Magnesium stearate } & 2 \cdot 87 & 0.27 \\ \text { Testosterone propionate } & 1.05 & - \\ \text { Oestradiol benzoate } & - & 1.05\end{array}$

These pellets were implanted under the skin through a steel tube, sharpened to penetrate the skin, by ejecting them with a steel plunger. Using this method the pellets could be deposited at a distance from the site of penetration and the risk that the rat could worry the pellet through the insertion site was minimized. It was found that the pellets retained some influence for about $2 \frac{1}{2}$ months, so they were renewed at this interval. When a rat was obviously senile or near death no fresh implant was made and none was made in a rat after 800 days of age.

The rats were kept in a room with artificial light during the daytime at a standard temperature of $70^{\circ} \mathrm{F}$. They were fed on unlimited Big Red dog pellets.

The groups, of fifty rats each, were as follows:

(I) Normal females, bred first at 100 days old and allowed to have their young which were weaned at 3 weeks old. The females were then re-bred. This routine was kept up throughout their lives.

(II) Normal females, bred first at 270 days, after which the same routine was followed as for Group I.

(III) Normal females, never bred.

(IV) Females ovariectomized between the ages of 38 and 42 days. A very few rats died after the operation. These were replaced.

(V) Normal males used for breeding Groups I and II. This amount of breeding may be described as light.

(VI) Normal males never used for breeding.

(VII) Males castrated between 39 and 42 days old. Any that died within a week of operation were replaced. 
(VIII) Females ovariectomized at 39 to 42 days old and then implanted with oestradiol benzoate pellets for the first time at ages that varied from 45 to 130 days. Implants were renewed at $2 \frac{1}{2}$-month intervals until the rats were 800 days old or senile.

(IX) Females ovariectomized at 39 to 42 days and then implanted with testosterone propionate pellets for the first time at ages that varied from 45 to 130 days. Implants were renewed as in Group VIII.

(X) Males castrated at 38 to 42 days old and implanted with oestradiol benzoate pellets for the first time at ages that varied from 45 to 130 days. Implants were renewed as in Group VIII.

(XI) Male rats castrated at 38 to 42 days old and implanted with testosterone propionate pellets at ages that varied between 45 and 130 days. Implants were renewed as in Group VIII.

The rats were weighed at monthly intervals and their condition noted if it was not normal. Cages were inspected daily and any dead animal was recorded and autopsied in an attempt to determine the cause of death. One rat in Group VIII was accidentally killed during the course of the experiment. She was replaced by another of approximately the same age which had been receiving oestradiol benzoate implants.

Choice of hormone dosage was arbitrary as there was no good indication of the level of hormones circulating in the blood of normal rats. Pellets were renewed at $2 \frac{1}{2}$ months because a study of growth records and activity in preliminary work showed that absorption was almost complete at the end of this period. The age at first implant varied because the initial arrangement for obtaining the pellets failed so that they were not immediately available. Analysis of the ages at death in the implanted groups showed no effect from the spread in implantation dates.

\section{RESULTS}

The average age at death for each group is given in Table 1 . The ages by which each $10 \%$ had died are given in Table 2 .

It is evident that the female rats outlived the males, whether they were bred or not, by a margin that varied from 6 to $20 \%$. This greater male mortality was apparent at all ages.

An analysis of variance indicates that there is some significant difference among groups. In order to establish which groups were significantly different from others, Duncan's New Multiple Range Test was applied to the data (Steel \& Torrie, 1960). The results of this comparison show that the differences in average life-span between groups are mostly not significant at the $5 \%$ level, the usually acceptable level of probability. The average age at death of Group III is significantly different from those of Groups VII, V, XI, IX and VI, while those of Groups I and X are only significantly different from the average of Group VI. No other differences are significant at this level.

Although the statistical significance of the differences between the other groups is lower than is usually regarded as acceptable, there is a certain symmetry about the results that gives some confidence in interpreting them. 
Castration lengthened the average life-span of the males while ovariectomy shortened that of the females. These two mean life-spans, Groups VII and IV, occur together as the middle terms of the range. All those with shorter lifespans were males or groups treated with testosterone. All those with longer

TABLE 1

MEAN AGES OF GROUPS OF RATS AT DEATH

\begin{tabular}{l|c|c}
\hline \multicolumn{1}{c|}{ Group } & $\begin{array}{c}\text { Mean age of } \\
\text { group at death } \\
(\text { days })\end{array}$ & $\begin{array}{c}\text { Standard } \\
\text { deviation } \\
\text { (days) }\end{array}$ \\
\hline 1. Females bred first at 100 days old; bred for rest of life & $697 \pm 26$ & 183 \\
2. Females bred first at 270 days old; bred for rest of life & $672 \pm 18$ & 128 \\
3. Females never bred & $742 \pm 24$ & 166 \\
4. Females ovariectomized at about 45 days old & $669 \pm 26$ & 181 \\
5. Males used for breeding & $635 \pm 19$ & 136 \\
6. Males not used for breeding & $615 \pm 21$ & 146 \\
7. Males castrated at about 45 days old & $651 \pm 26$ & 185 \\
8. Females ovariectomized at about 45 days and implanted with & $671 \pm 22$ & 155 \\
oestrogens & $625 \pm 21$ & 145 \\
9. Females ovariectomized at about 45 days and implanted with & $699 \pm 23$ & 160 \\
androgens & $634 \pm 21$ & 147 \\
10. Males castrated at about 45 days and implanted with oestrogens & \\
11. Males castrated at about 45 days and implanted with androgens & \\
\hline
\end{tabular}

life-spans were females or groups treated with oestrogens. These results indicate that testosterone shortens the life-span while oestrogens tend to lengthen it. This second statement needs some qualification which is given later in this paper.

TABLE 2

AGE AT DEATH OF RATS BY DECILES

\begin{tabular}{|c|c|c|c|c|c|c|c|c|c|c|}
\hline \multirow{2}{*}{ Group } & \multicolumn{10}{|c|}{$\%$ Dead } \\
\hline & 10 & 20 & 30 & 40 & 50 & 60 & 70 & 80 & 90 & 100 \\
\hline $\begin{array}{r}\text { I } \\
\text { II } \\
\text { III } \\
\text { IV } \\
\text { V } \\
\text { VI } \\
\text { VII } \\
\text { VIII } \\
\text { IX } \\
\underset{X}{X I}\end{array}$ & $\begin{array}{l}383 \\
557 \\
550 \\
428 \\
410 \\
335 \\
399 \\
475 \\
444 \\
483 \\
443\end{array}$ & $\begin{array}{l}568 \\
598 \\
593 \\
493 \\
564 \\
527 \\
502 \\
527 \\
524 \\
584 \\
500\end{array}$ & $\begin{array}{l}664 \\
627 \\
650 \\
573 \\
597 \\
581 \\
602 \\
578 \\
558 \\
637 \\
529\end{array}$ & $\begin{array}{l}687 \\
651 \\
682 \\
644 \\
624 \\
611 \\
632 \\
623 \\
606 \\
658 \\
601\end{array}$ & $\begin{array}{l}715 \\
691 \\
720 \\
685 \\
633 \\
616 \\
665 \\
687 \\
645 \\
671 \\
629\end{array}$ & $\begin{array}{l}724 \\
701 \\
753 \\
709 \\
654 \\
657 \\
696 \\
730 \\
680 \\
684 \\
656\end{array}$ & $\begin{array}{l}740 \\
717 \\
803 \\
732 \\
662 \\
698 \\
727 \\
755 \\
691 \\
781 \\
702\end{array}$ & $\begin{array}{l}858 \\
728 \\
886 \\
782 \\
719 \\
736 \\
770 \\
796 \\
745 \\
839 \\
756\end{array}$ & $\begin{array}{l}928 \\
824 \\
972 \\
939 \\
806 \\
757 \\
875 \\
842 \\
765 \\
885 \\
836\end{array}$ & $\begin{array}{r}1084 \\
963 \\
1152 \\
1047 \\
974 \\
896 \\
1127 \\
1059 \\
974 \\
992 \\
954\end{array}$ \\
\hline
\end{tabular}

If Groups VI, IX, XI, V and VII (the males or testosterone-treated animals) are combined, and Groups IV, VIII, II, X, I and III (females or those treated with oestrogens) are also combined, the difference in average age at death 
between these major groups is 59.7 days $(632.0$ and 691.7$)$. This difference is highly significant, as 26.6 days is the least significant difference.

Ovariectomy has little effect upon the age at which $50 \%$ are dead as the reduction observed at this point was small. However, it does shorten the average life-span by reducing the extreme age to which the rats live. This is seen in comparing this group (IV) with the unbred females (III); with bred females (I and II) the difference is much less. It has a delayed effect.

Castration of the males (VII) increased the median survival age and also the average age at death over those for the normal males (V and VI). The increase approached, but did not quite equal, the corresponding ages for the ovariectomized rats (IV), but the change lacked significance at the $5 \%$ level.

Ovariectomized females implanted with oestrogens (VIII) had a median survival age and an average age at death closely corresponding with those found for the unimplanted ovariectomized rats (IV). Castrated males implanted with androgens (XI) had a reduced median survival and reduced average life-span. Both these figures were reduced to a point corresponding with the ages for normal males ( $\mathrm{V}$ and $\mathrm{VI})$. The advantages of castration have disappeared under the influence of the androgen implants, but again the figures lack the degree of significance desirable.

The greater survival rate and the increased average life-span of the castrated males and the reduced figures for both gonadectomized males and females with testosterone propionate implants support Hamilton's (1948) hypothesis that testosterone tends to reduce the life-span. The evidence in regard to oestrogens is not so clear. Oestradiol benzoate tended to prolong the life-span of the castrate male but it was without effect upon the ovariectomized female. At the same time our data do tend to support Slonaker's (1930) view that the presence of ovaries is conducive to longer life.

Evidently not all strains of rats respond to gonadectomy as did ours. Talbert \& Hamilton (1965) have found in the Lewis strain that castration lengthened life but not to a statistically significant extent. This result corresponds with ours. But they found that spaying may lengthen life, again without statistical significance to the change. This was contrary to our figures which showed an insignificant statistical shortening of the life-span.

Oestrogen implants caused the rats of both sexes to lose weight, but they gradually made this up as the effects of the implants wore off. At the same time the rats became restless and tended to chew off fragments of the feed pellets and drop them through the cage floor. Testosterone implants were followed by a small immediate weight gain but this was lost in a few days. In view of the general interest in a possible relationship between rate of growth and longevity the groups may be compared. They all grew at about the same relative rate but plateaued at different weights. Accordingly, the plateau weight is a reasonable indication of the growth rate. Normal males, whether used for breeding or not, reached approximately $400 \mathrm{~g}$ and they were amongst the groups with the shortest life-spans. Castrate males and the castrates receiving testosterone plateaued at about $330 \mathrm{~g}$. The latter were amongst the shortest lived while the former were intermediate. Females used for breeding (100 days), ovariectomized females and those with testosterone, also castrates with oestrogens, 
plateaued at from 265 to $275 \mathrm{~g}$. All these groups, except the ovariectomized females with testosterone, were amongst the longer lived; the exception was amongst the shorter lived. The unbred females, also those bred first at 270 days and the ovariectomized females with oestrogen implants plateaued at 225 to $230 \mathrm{~g}$. The unbred females lived longest, but the other two groups were intermediate in their longevity. Thus there is a fairly good inverse correlation between the plateau weight of groups and the group longevity.

The apparent effects of breeding upon longevity in the females are not significant at the $5 \%$ level. However, the unbred females (III) outlived those that had been bred (I). The increase was entirely due to a prolongation of the life-span at its extreme, not to any lessened mortality early in life. Late breeding (II), at 270 days for the first time in contrast to breeding at 100 days, had some further adverse effect, but not much and it was most apparent in its effect upon early mortality. This is contrary to the experience of Slonaker (1928) whose unbred females averaged 890 days at death and whose normally bred rats averaged 923 days, while those limited to two or three litters averaged 981 days. But Arvay, Takacs \& Verzar (1963) found that collagen aged faster in rats that had been pregnant than amongst those that had not been bred, and the ageing of this tissue is regarded as a good indication of physiological age. In mice, Mühlbock (1959a, b) reports that in the DBA and CBA strains unmated females live longer than bred ones. Gowen (1960) regards the greater longevity of female mice exposed to single sub-lethal X-ray doses as due wholly to the suspension of litter bearing. But, in man, statistics show that unmarried women have a shorter life expectation than those that are married. This may be due in part to selection; those in poor health may be less likely to marry than those in better health. Also, Sheps (1961) has given reasons for believing that the census data dealing with this subject contain many inaccuracies.

Our data for males show little or no difference in the longevity of the bred and unbred rats. Slonaker (1928) concluded that there was little difference in the life-span of unbred male rats and those used very heavily for breeding, but his unbred sample contained only four animals and his heavily used group twelve. Similar small groups of four each used for various amounts of breeding from little to heavy, had longer life-spans than either of those already quoted. Agduhr \& Barron (1938) have shown that regular breeding improves the condition and longevity of male rats exposed to the influence of the drug, medinal.

One may conclude from the consistency of our data that breeding shortens the life-span of the female, but valid statistical significance is lacking. At the same time the presence of ovaries seems to be an advantage while oestradiol in the amounts used does not replace their influence. This may indicate that another ovarian factor is responsible for prolonging life. As it is not likely that the unbred rats were under the influence of active corpora lutea for much of their lives we are at present unable to account for the life-prolonging influence of the ovaries. The problem deserves further study. Slonaker (1930) had a large group of rats that were hysterectomized and then kept with males. These may have been continuously pseudopregnant. These rats had a shorter life-span by 105 days than did similar rats kept unmated. Thus the influence of the corpus luteum may account for the shorter life-span of pregnant females but 
it does not explain why normal females live longer than those that have been ovariectomized.

\section{ACKNOWLEDGMENTS}

We thank Dr G. M. McCay for his interest and advice during the progress of this work. Also Mrs R. Seither and Mr H. Sisson for their care of the rats through several years.

This investigation was supported by U.S. Public Health Service Research Grant No. A-3299 Endo. from the Institute for Arthritis and Metabolic Diseases.

\section{REFERENCES}

Agduhr, E. \& BARron, D. H. (1938) Further observations on the increased resistance of mated animals to toxic agents-medinal. Archs int. Pharmacodyn. Ther. 58, 351.

Arvay, A., Takacs, J. \& Verzar, F. (1963) Der Einfluss von Graviditäten auf das Altern des Collagens. Gerontologia, 7, 77.

Curtis, M., Dunning, W. \& Bullock, F. (1933) Genetic factors in relation to the etiology of malignant tumors. Am. F. Cancer, 17, 894.

Dublin, L. I., Lotka, A. J. \& Spiegelman, M. (1949) Length of life. A study of the life table. Ronald Press, New York.

Gowen, J. W. (1960) Biology of ageing; A symposium, pp. 188-191. Ed. B. L. Strehler. Publications of the American Institute of Biology, Washington.

Hamilton, J. B. (1948) The role of testicular secretions as indicated by the effects of castration in man and by studies of pathological conditions and the short lifespan associated with maleness. New York. Recent Prog. Horm. Res. 3, 257.

HamiLton, J. B. (1965) Relationship of castration, spaying and sex to survival and duration of life in domestic cats. 7. Geront. 20, 96.

McCay, C. M., Sperling, G. \& Barnes, L. (1943) Growth, ageing, chronic diseases and lifespan in rats. Archs Biochem. 2, 469.

MüнLвоск, O. (1959a) Factors influencing the lifespan of inbred mice. Gerontologia, 3, 177.

MüнLвоск, O. (1959b) Discussion, In: The Lifespan of Animals, p. 287. Eds. G. E. W. Wolstenholme and M. O'Connor. Little Brown, Boston, Massachussetts.

Robertson, T. B., Marston, H. R. \& Walters, J. W. (1934) Influence of intermittent starvation and of intermittent starvation plus nucleic acid on growth and longevity of white mouse. Aust. $\mathcal{F}$. exp. Biol. med. Sci. 12, 33.

Sheps, M. C. (1961) Marriage and mortality. Am. J. publ. Hlth, 51, 547.

Slonaker, J. R. (1928) Effect of different amounts of sexual indulgence in the albino rat. VI. Lifespan and cause of death. Am. F. Physiol. 85, 106.

Slonaker, J. R. (1930) The effect of the excision of different sexual organs on the development, growth and longevity of the albino rat. Am. 7. Physiol. 93, 307.

Steel, R. G. D. \& Torrie, J. H. (1960) Principles and procedures of statistics, pp. 107-109. McGraw-Hill, New York.

Talbert, G. B. \& Hamilton, J. B. (1965) Duration of life in Lewis strain of rats after gonadectomy at birth and at older ages. F. Geront. 20, 489. 